\title{
Successful surgical management of invasive pulmonary fungal infection in patients with leukemia
}

\author{
Ming Dong* \\ Xin $\mathrm{Li}^{*}$ \\ Jinghao Liu* \\ Zuoqing Song \\ Honglin Zhao \\ Sen Wei \\ Gang Chen \\ Jun Chen
}

Department of Lung Cancer Surgery, Tianjin Medical University General Hospital, Tianjin Key Laboratory of Lung Cancer Metastasis and Tumor Microenvironment, Tianjin Lung Cancer Institute, Tianjin 300052, People's Republic of China

*These authors contributed equally to this work
This article was published in the following Dove Press journal: Infection and Drug Resistance

Background: Invasive pulmonary aspergillosis (IPA) is an opportunistic fungal infection affecting patients who are undergoing chemotherapy for hematological malignancies, have hematopoietic stem cell transplants, and are immunosuppressed. Surgical treatment for IPA is remains challenging and controversial due to the potentially high risk of mortality and morbidity.

Methods: We discuss 4 leukemia patients who underwent surgery for IPA in our hospital who were successfully treated with curative lobectomy or wedge resection. All patients had uneventful postoperative courses, and all resumed long-term follow-up for their leukemia.

Results: All patients have suffered at least once of hemoptysis with radiological findings of lung nodules appearing as ovoid soft-tissue opacities in the lung parenchyma and had undergone antifungal agent treatment for at least 2 weeks. The symptoms and infection sites were not better. Lobectomy was performed in 3 cases and wedge resection in 1 case. Two of the cases suffered Aspergillus infection, 1 suffered Trichoderma and 1 suffered Candida albicans. Median hospital stay after surgery was 17.25 days. There was only 1 patient who had prolonged air leak $(n=1 ; 25 \%)$ with empyema. There were no mortalities during the perioperative period or within 30 days of surgery, all patients survived without recurrence and resumed anti-leukemia treatment as soon as possible.

Conclusion: Surgical resection of focal invasive pulmonary aspergillosis can be a safe and feasible treatment option in appropriately selected cases.

Keywords: invasive pulmonary fungal infection, leukemia, lobectomy, treatment, prognosis

\section{Introduction}

Fungal infection is a ubiquitous pathogen. Invasive pulmonary fungal infections such as aspergillosis, less commonly mucormycosis, and fusariosis are serious and potentially deadly complication of myelosuppressive chemotherapy in patients with hematological malignancies. ${ }^{1}$ Opportunistic fungal infections have been estimated to affect over 200,000 people worldwide, and invasive pulmonary aspergillosis (IPA) is relatively common in immunocompromised and critically ill patients, ${ }^{2}$ including those who are undergoing chemotherapy for hematological malignancies, hematopoietic stem cell transplant (HSCT), or other forms of immunosuppression. ${ }^{3}$ Patients who are undergoing allogeneic HSCT or remission induction chemotherapy for acute myelogenous leukemia/myelodysplastic syndrome (AML/MDS) are at an especially high risk, with 20-fold higher rates of aspergillosis compared to patients with underlying lymphoma or multiple myeloma. ${ }^{4}$ The incidence of IPA during
Department of Lung Cancer Surgery, Tianjin Medical University General Hospital, Tianjin Key Laboratory of Lung

Cancer Metastasis and Tumor Microenvironment, Tianjin Lung Cancer Institute, Anshan Road No. 154, Heping District, Tianjin 300052, People's Republic of China

Tel +862260814803

Email huntercj2004@yahoo.com 
bone marrow transplantation is about $5 \%$, and mortality rates as high as $82 \%$, despite antifungal treatment, are reported. ${ }^{5}$ Furthermore, treatment with antifungal medications may interrupt life-saving cancer chemotherapy in these patients. ${ }^{1}$ In addition, some fungal infection abutting the main pulmonary vessels is the cause of fatal hemoptysis. ${ }^{2}$ Despite aggressive treatment with new or more antifungal agents, these infections are an important cause of morbidity and mortality, especially in these cases. Surgery for IPFI is infrequently and the secondary choice. There are few reports about the perioperative management. Although risk assessment is imprecise and new antifungal medications may ameliorate some surgical risks, controversy remains regarding the surgical management of IPA. Surgery has traditionally been reserved for patients with unilateral localized fungal infection, for which curative resection is possible, or for patients with infection abutting the main pulmonary vessels, who may be at risk of fatal hemoptysis. ${ }^{2,6}$ Some researchers also reported that single or multiple Aspergillus nodules, which may or may not be cavitating, were risk factors for carcinoma of the lung, making biopsy or surgical resection inevitable. ${ }^{7}$ However, the opportunity, method and indication of surgical treatment these patients were not described. We herein present 4 cases of IPFI in patients with underlying leukemias that were treated with curative resection. We try to discuss the opportunity, method, indication, outcomes, and the perioperative treatment of surgical treatment for IPFI.

\section{Methods}

Four leukemia patients with IPA were identified from the Department of Lung Surgery, Tianjin Medical General Hospital, Tianjin, China. The diagnosis of IPA was confirmed by colony isolation in culture and histologic documentation of hyphae in tissue samples. Hematoxylin and eosin-stained sections were reviewed in all cases. ${ }^{8}$

Table I Preoperative data of four patients

\begin{tabular}{|c|c|c|c|c|c|c|}
\hline $\begin{array}{l}\text { Patient } \\
\text { no. }\end{array}$ & Age/sex & $\begin{array}{l}\text { Underlying } \\
\text { disease }\end{array}$ & Chemotherapy & Antifungal therapy & $\begin{array}{l}\text { Time from diagno- } \\
\text { sis to operation }\end{array}$ & Culture \\
\hline I & $51 /$ male & AML & DA & $\begin{array}{l}\text { Caspofungin } \\
70 \mathrm{mg} \text { DI, } 50 \mathrm{mg} \text { DI DI0 }\end{array}$ & 13 days & Trichoderma \\
\hline 2 & I8/male & $\begin{array}{l}\text { Erythroleukemia/ } \\
\text { MDS }\end{array}$ & IA & None & 3 days & Aspergillus \\
\hline 3 & $47 /$ female & APL & Retin-A+IA & $\begin{array}{l}\text { Voriconazole } \\
6 \mathrm{mg} / \mathrm{kg} \text { ivdrip Q12 DI, } 4 \mathrm{mg} / \mathrm{kg} \\
\text { ivdrip Q12 D2 D5 }\end{array}$ & 5 days & Aspergillus \\
\hline 4 & $23 /$ male & AML & DA & $\begin{array}{l}\text { Voriconazole } \\
6 \text { mg/kg ivdrip Q12 DI, } 4 \text { mg/ } \\
\text { kg ivdrip Q12 D2 14 }\end{array}$ & 17 days & $\begin{array}{l}\text { Candida } \\
\text { albicans }\end{array}$ \\
\hline
\end{tabular}

Abbreviations: AML, acute myeloid leukemia; APL, acute promyelocytic leukemia; MDS, myelodysplastic syndrome; DA, daunorubicin + cytosine arabinoside; IA, idarubicin + cytosine arabinoside.

Table 2 Operative and postoperative data of four patients

\begin{tabular}{|l|l|l|l|l|l|l|l|}
\hline $\begin{array}{l}\text { Patient } \\
\text { no. }\end{array}$ & Operation & Complications & $\begin{array}{l}\text { Antifungal } \\
\text { therapy }\end{array}$ & $\begin{array}{l}\text { Hospital } \\
\text { stay }\end{array}$ & $\begin{array}{l}\text { Cost } \\
\text { (USD) }\end{array}$ & $\begin{array}{l}\text { Follow- } \\
\text { up }\end{array}$ & Outcome \\
\hline 1 & Lobectomy & None & Caspofungin & 13 days & $\$ 11,291$ & 3 months & $\begin{array}{l}\text { Alive, reinduction } \\
\text { chemotherapy }\end{array}$ \\
\hline 2 & Lobectomy & None & Voriconazole & 14 days & $\$ 20,788$ & 3 months & $\begin{array}{l}\text { Alive, reinduction } \\
\text { chemotherapy }\end{array}$ \\
\hline 3 & $\begin{array}{l}\text { Wedge } \\
\text { resection }\end{array}$ & None & Voriconazole & 20 days & $\$ 15,009$ & 3 months & $\begin{array}{l}\text { Alive, reinduction } \\
\text { chemotherapy }\end{array}$ \\
\hline 4 & Lobectomy & $\begin{array}{l}\text { Prolonged air leak, } \\
\text { empyema }\end{array}$ & Voriconazole & 22 days & $\$ 19,648$ & 3 months & $\begin{array}{l}\text { Alive, reinduction } \\
\text { chemotherapy }\end{array}$ \\
\hline
\end{tabular}


Salient clinical features are summarized in Tables 1 and 2. Four patients who were receiving chemotherapy for hematologic malignancies, 3 men and 1 woman, aged 18-51 years (mean 34.75 years), underwent curative resection for IPA. Presenting symptoms included cough, hemoptysis, fever, and chest pain.

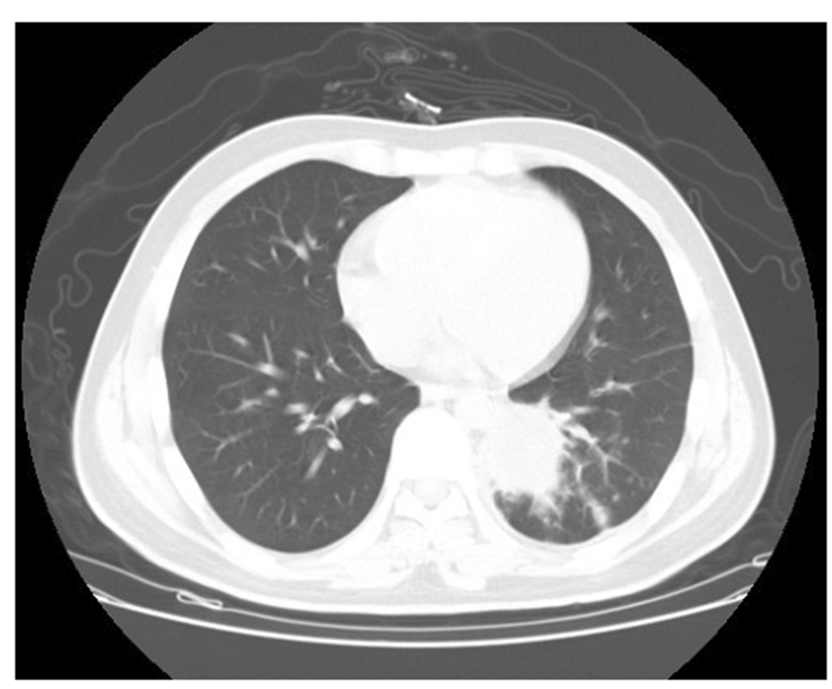

Figure I Aspergilloma on chest computed tomography (Patient 2). The lesion is visible as a cavitation within normal lung tissue in the left lower lobe.

\section{Results}

All patients had radiological findings of lung nodules appearing as ovoid soft-tissue opacities in the lung parenchyma, size $>1 \mathrm{~cm}$, obscuring the underlying bronchovasculature, with or without a halo sign, which is defined as a perimeter of ground glass opacity surrounding the nodule through which the background of underlying bronchovasculature remains visible, as shown in Figure 1. Complete remission of leukemia was demonstrated by normal white blood cell, neutrophil, red blood cell, and platelet counts. Baseline serum chemistry screening and urinalysis at admission were normal. All of 4 patients have suffered at least once of hemoptysis and antifungal agents' treatment at least two weeks. The symptoms and infection sites were not better (Table 1).

Curative resection of the nodules was achieved by lobectomy in 3 cases and wedge resection in 1 case. All of these operations were video-assisted thoracic surgery (VATS). All patients received postoperative antifungal therapy.

Histopathological examination of the resected specimens showed IPA nodules characterized by areas of central necrosis containing numerous hyphae and surrounded

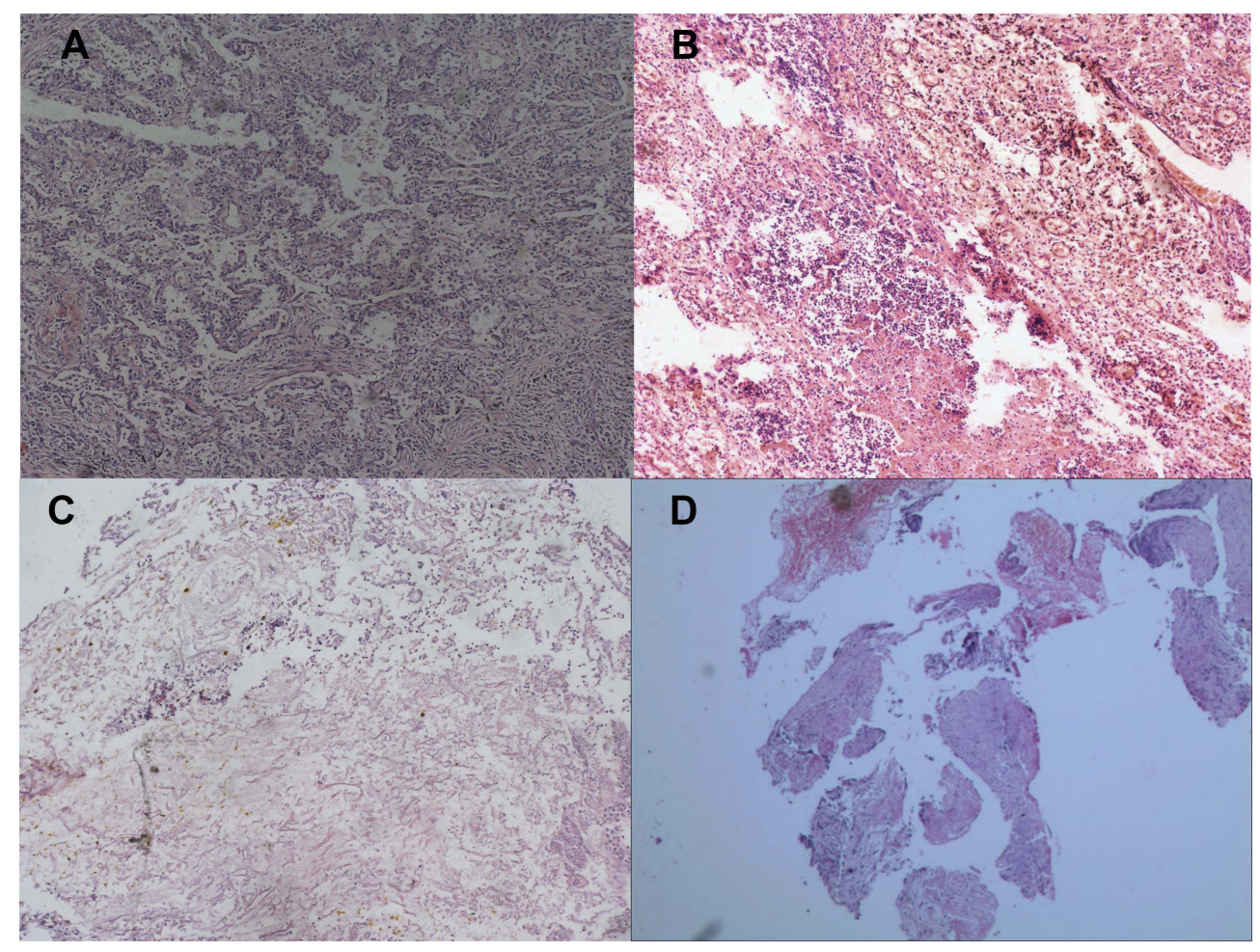

Figure 2 Histopathology of patients. Broad septated hyphae mixed with non-septated hyphae are visible in tissue sections. (A) Patient I, Trichoderma; (B) Patient 2, Aspergillus; (C) Patient 3, Aspergillus; (D) Patient 4, Candida albicans. (hematoxylin and eosin. $\times 100$ ). 
by granulomatous inflammation with scattered multinucleate giant cells. Hyphae are the most important characteristic for the identification of aspergillosis. The surrounding lung parenchyma showed fibrosis and a chronic inflammatory cell infiltrate (Figure 2). Two of the cases suffered Aspergillus infection, 1 suffered Trichoderma, and 1 suffered Candida albicans.

Median hospital stay after operation was 17.25 days (range 14-22 days). The average cost was $\$ 16,684$ (range $\$ 11,291$ to $\$ 20,788)$. Among the 4 patients, 1 patient had prolonged air leak $(n=1 ; 25 \%)$ and the same patient $(n=1,25 \%)$ had empyema. There were no mortalities during the perioperative period or within 30 days after surgery, and all patients survived without recurrence and resumed anti-leukemia treatments as soon as possible (Table 2).

\section{Discussion}

Patients with AML/MDS who are undergoing remission induction chemotherapy are at especially high risk of aspergillosis, with an estimated 20-fold higher rate of infection compared to patients with underlying lymphoma or multiple myeloma. ${ }^{4}$ Recent diagnostic advances and newer antifungal therapies have been associated with improved survival rates, but invasive fungal infection is still fatal in up to one-third of cases, and furthermore, affected patients may face an interruption of life-saving cancer chemotherapy during treatment of the mold infection. $^{1,9}$

The diagnosis of IPFI can be challenging, as up to onethird of patients may have no early clinical signs or may present with non-specific signs, such as progressive fever and cough. Pneumothorax and chest pain may also accompany IPFI. ${ }^{10}$ Thoracic computed tomography (CT) can be essential to diagnosis, particularly for IPA, when typical findings are present with an early halo sign. The halo sign is highly specific for IPA during the early stages of the infection but usually disappears after about 14 days. During the later course of IPA, a crescent air sign may be present. This sign is suggestive of IPA, but it is not as specific as the halo sign. Bronchoalveolar lavage (BAL) or other laboratory tests may lack sensitivity, ${ }^{11}$ and lung biopsy, quantitative real-time polymerase chain reaction, or galactomannan assay (ie, the Platelia ${ }^{\circledR}$ brand assay) of BAL fluid are additional diagnostic tools. ${ }^{12}$ In our patients, diagnosis was based on serial CT scans and clinical findings.

Aggressive treatment with antifungal agents is the first choice for these patients. However, in some special cases, such as long-term treatment with antifungal medications may interrupt life-saving cancer chemotherapy or infection abutting the main pulmonary vessels, who may be at risk of fatal hemoptysis, surgical treatment maybe a good choice. Aggressive surgical resection has still been associated with improved outcome, although invasive aspergillosis is a multifocal disease at least at microscopic level, even surgical excision does not guarantee a complete cure. ${ }^{13}$ One of surgical intervention is indicated for patients with hemoptysis. Especially when medical treatment is ineffective for hemoptysis, surgery offers an efficacy therapeutic option. Caillot et al showed that aggressive surgery has a role in preventing fatalities due to massive hemorrhages in patients with invasive pulmonary aspergillosis and hemoptysis. ${ }^{14}$

Surgical intervention is also indicated for patients with radiologic findings suggesting persistence of IPA cavities because persistent intracavitary fungal growth is associated with a high risk of relapse in patients who are neutropenic from chemotherapy or immunosuppression. Furthermore, long-term treatment with ineffective antifungal medications may interrupt life-saving cancer chemotherapy in these patients. ${ }^{1}$ The standard surgical approaches to localized pulmonary mycoses include anatomic pulmonary resection, such as segmentectomy or lobectomy, while wedge resection should be reserved for patients with small, simple lesions, and pneumonectomy may be indicated for those with overlapping areas of destroyed lung tissue. ${ }^{15}$ All 4 patients had resection of infection sites via video-assisted thoracoscopic surgery (VATS). VATS, in comparison with open lobectomy, has been associated with relatively improved prognosis, decreased morbidity, less complications, shorter anesthesia times, and reduced length of hospital stay. ${ }^{16}$ The less complications and reduced length of hospital stay allowed the patients to continue the treatment of leukemia as soon as possible.

However, antifungal therapy remains the mainstay of treatment for invasive fungal infection. ${ }^{17}$ Perioperative antifungal treatments may also be warranted until clinical symptoms have been relieved. It has been shown that the combination of antifungal treatment and surgical resection can improve the prognosis of invasive fungal infection. When the risk of leukemia relapse or the presence of multiple and bilateral lesions does not allow for the surgery, secondary antifungal prophylaxis is the main option for such patients. The recent updated guidelines of the European Conference on Infectious Complications in 
Table 3 Literature review of the leukemia patients with IPA

\begin{tabular}{|c|c|c|c|c|c|c|}
\hline Patients & Period & Underlying disease & $\begin{array}{l}\text { Operative } \\
\text { procedure (\%) }\end{array}$ & $\begin{array}{l}\text { Operative mortal- } \\
\text { ity/morbidity (\%) }\end{array}$ & $\begin{array}{l}\text { Histology for } \\
\text { Aspergillus } \\
\text { (\%) }\end{array}$ & Author \\
\hline 16 & $1987-1993$ & AML (14), LTX (2) & $\begin{array}{l}P(12.5), L(62.5), \\
W(25)\end{array}$ & $31.2 / 12.5$ & 56.3 & Robinson et al $^{18}$ \\
\hline 15 & $1988-1997$ & AML (15) & L (53), W (47) & $6.7 / 13.2$ & 100 & Bernard et al ${ }^{19}$ \\
\hline 18 & $1988-1996$ & $\begin{array}{l}\text { AML (I3), ALL (3), Myeloma } \\
\text { ( 2) }\end{array}$ & $\begin{array}{l}P(5.6), L(6 \mid . I), \\
W(33.3)\end{array}$ & O/unknown & 66.6 & Baron et $\mathrm{al}^{20}$ \\
\hline 27 & $1983-1997$ & $\begin{array}{l}\text { AML (II), ALL (4), AA (7), } \\
\text { CML (3), NHL (I), MDS (I) }\end{array}$ & L (74), W (26) & $1.4 / 18.5$ & 81.5 & $\begin{array}{l}\text { Reichenberger } \\
\text { et } \mathrm{al}^{21}\end{array}$ \\
\hline 13 & $1986-1996$ & $\begin{array}{l}\operatorname{AML}(6), \operatorname{ALL}(3), \operatorname{MDS}(I), \\
\text { HL (I), AA (I), MM (I) }\end{array}$ & L (34), W (77) & $7.6 / 7.6$ & n.g & Salerno et $\mathrm{al}^{22}$ \\
\hline 13 & $1988-1998$ & $\begin{array}{l}\text { AML (6), ALL (6), breast } \\
\text { cancer (I) }\end{array}$ & $\begin{array}{l}P(7.6), L(30.8), \\
W(61.6)\end{array}$ & $15.3 / 15.3$ & 76 & $\begin{array}{l}\text { Pidhorecky } \\
\text { et } \mathrm{al}^{23}\end{array}$ \\
\hline 35 & $1982-1995$ & $\begin{array}{l}\text { n.g, all patients received } \\
\text { BMT }\end{array}$ & P (I I), L (89) & $22.8 / 11.4$ & 100 & Yeghen.et $\mathrm{al}^{24}$ \\
\hline 10 & $|99|-2000$ & AML(6), ALL(3) & L (80), W (20) & $0 / 20$ & 40 & Al-Kattan et $\mathrm{al}^{25}$ \\
\hline $4 I$ & $1983-2002$ & $\begin{array}{l}\text { A/CML (26), AA (7), NHL } \\
\text { (8) }\end{array}$ & $\begin{array}{l}\text { L (56), W (39), } \\
E(5)\end{array}$ & $10 / 10$ & 75.6 & Matt et $\mathrm{al}^{26}$ \\
\hline 10 & $200 \mathrm{I}-2007$ & $\begin{array}{l}\text { AML (4), ALL (4), LTx (I), } \\
\mathrm{NHL}(\mathrm{I})\end{array}$ & $L(60), W(40)$ & $20 / 10$ & 60 & Danner et $\mathrm{al}^{5}$ \\
\hline
\end{tabular}

Abbreviations: A/CML, acute/chronic myeloid leukaemia; ALL, acute lymphoblastic leukemia; (N)HL, (Non)Hodgkin lymphoma; AA, aplastic anemia; MM, multiple myeloma; BMT, bone marrow transplantation; LTx, liver transplantation; MDS, myelodysplastic syndrome; P, pneumectomy; L, lobectomy; W, wedge resection/segmentectomy; E, enucleation; n.g., not given; po, postoperative.

Leukemic patients stated that combination antifungal therapy is optional in patients who need rescue treatment. Three of the 4 patients were treated with preoperative antifungal medications (voriconazole or caspofungin), and all patients received postoperative voriconazole or Amphotericin B (Table 2). All of our 4 patients were able to resume antileukemia treatments within 3 months after surgery.

The results of our literature review are summarized in Table 3. As yet, no randomized prospective trial identifying an optimal treatment, including antifungal therapies and surgical approaches, has been reported. And the treatment with antifungal agents is the first choice for IPFI patients. But in some special cases, surgical resection may be indicated in patients with progressive disease, in those with stable radiological findings during antifungal treatment, in those who require further immunosuppressive treatment for underlying malignancies, in those who with non-disseminated mycoses, and in those who may be at risk of fatal hemoptysis after antifungal agents' treatment. In our patients, surgical intervention allowed prompt, curative treatment of IPA at a relatively low cost, and patients were able to resume their anti-leukemia treatments as early as possible. In planning the surgical procedure, the size of the fungal infection site and the underlying pulmonary disease must be considered. The main goal is to resect the mycotic site, including afferent pulmonary vessels. At the same time, because most patients will have decreased pulmonary reserve, the parenchymal resection should be limited as much as possible to avoid further impairment to lung function. As noted, VATS resection, when possible, can be expected to reduce the risk of comorbidity and allow for shorter anesthesia times and a shorter hospital stay.

\section{Conclusion}

IPFI is a potentially fatal complication of chemotherapy or immunocompromise in patients with leukemia, and mortality rates may reach $100 \%$ without treatment. ${ }^{5}$ The standard treatment is antifungal chemotherapy and recovery of immunocompetence. Surgery may be 
indicated for patients with risk of fatal hemoptysis, and long-term treatment with ineffective antifungal medications may interrupt life-saving cancer chemotherapy. Perioperative antifungal treatments may also be warranted until clinical symptoms have improved. Further related multicenter studies are required to determine the role of surgical treatment of IPA in patients with leukemia, particularly in the context of immunosuppressive and chemotherapy.

\section{Abbreviation list}

IPFI, invasive pulmonary fungal infection; IPA, invasive pulmonary aspergillosis; HSCT, hematopoietic stem cell; AML/MDS, Acute myelogenous leukemia/myelodysplastic syndrome; BAL, Bronchoalveolar lavage; VATS, video-assisted thoracoscopic surgery.

\section{Ethics approval and consent to participate}

This study was conducted in accordance with the standards of the Declaration of Helsinki for medical research involving human subjects. All patients provided written informed consent for the publication of this report and the accompanying images, and the study protocol was approved by the clinical research ethical review board at Tianjin Medical University General Hospital.

\section{Consent for publication}

Written informed consents were obtained from the patients for publication of this report and the accompanying images.

\section{Availability of data and materials}

All relevant data were within the paper.

\section{Acknowledgments}

This work was financially supported by grants from the National Natural Science Foundation of China (81773207, 81600073), the Science and Technology Support Key Program of Tianjin (17YFZCSY00840), Tianjin Key Project of Natural Science Foundation (16JCZDJC34200, 16PTSYJC00160) and Wu Jieping Medical Foundation (to Ming Dong, No. 320.6750.18157), and the Special Program of Talents Development for High Level Innovation and Entrepreneurship Team in Tianjin. The funders had no role in study design, data collection and analysis, decision to publish, or in the preparation of the manuscript.

\section{Author contributions}

All authors contributed to data analysis, drafting and revising the article, gave final approval of the version to be published, and agree to be accountable for all aspects of the work.

\section{Disclosure}

The authors declare that they have no competing interests in this work.

\section{References}

1. Stanzani M, Lewis RE, Fiacchini M, et al. A risk prediction score for invasive mold disease in patients with hematological malignancies. PLoS One. 2013;8:e75531. doi:10.1371/journal.pone.0075531

2. Brown GD, Denning DW, Gow NAR, Levitz SM, Netea MG, White TC. Hidden killers: human fungal infections. Sci Transl Med. 2012;4:165rv113. doi:10.1126/scitranslmed.3004404

3. Brasier AR, Zhao Y, Spratt HM, et al. Improved detection of invasive pulmonary aspergillosis arising during leukemia treatment using a panel of host response proteins and fungal antigens. PLoS One. 2015;10:e0143165. doi:10.1371/journal.pone.0143165

4. Pagano, L, Caira M, Candoni A, et al. The epidemiology of fungal infections in patients with hematologic malignancies: the SEIFEM-2004 study. Haematologica. 2006;91:1068-1075.

5. Danner BC, Didilis V, Dörge H, Mikroulis D, Bougioukas G, Schöndube FA. Surgical treatment of pulmonary aspergillosis/mycosis in immunocompromised patients. Interact Cardiovasc Thorac Surg. 2008;7:771-776. doi:10.1510/icvts.2007.171579

6. Cesar JM, Resende JS, Amaral NF, Alves CM, Vilhena AF, Silva FL. Cavernostomy $\mathrm{x}$ resection for pulmonary aspergilloma: a 32-year history. J Cardiothorac Surg. 2011;6:129. doi:10.1186/1749-80906-129

7. Farid S, Mohamed S, Devbhandari M, et al. Results of surgery for chronic pulmonary Aspergillosis, optimal antifungal therapy and proposed high risk factors for recurrence-a National Centre's experience. J Cardiothorac Surg. 2013;8:180. doi:10.1186/1749-80908-180

8. Walsh TJ, Anaissie EJ, Denning DW, et al. Treatment of aspergillosis: clinical practice guidelines of the Infectious Diseases Society of America. Clin Infect Dis. 2008;46:327-360. doi:10.1086/525258

9. Pagano L, Caira M, Candoni A, et al. Invasive aspergillosis in patients with acute myeloid leukemia: a SEIFEM-2008 registry study. Haematologica. 2010;95:644-650. doi:10.3324/ haematol.2009.012054

10. Luo BL, Zhang LM, Hu CP, Xiong Z. Clinical analysis of 68 patients with pulmonary mycosis in China. Multidiscip Respir Med. 2011;6:278-283. doi:10.1186/2049-6958-6-5-278

11. Cadena J, Thompson GR 3rd, Patterson TF. Invasive aspergillosis: current strategies for diagnosis and management. Infect Dis Clin North Am. 2016;30:125-142. doi:10.1016/j.idc.2015.10.015

12. Zhang S, Wang S, Wan Z, Que C, Li R, Yu J. Quantitative real-time PCR and platelia galactomannan assay for the diagnosis of invasive pulmonary aspergillosis: bronchoalveolar lavage fluid performs better than serum in non-neutropaenic patients. Mycopathologia. 2016;181:625-629. doi:10.1007/s11046-016-0024-5 
13. Offner F, Cordonnier C, Ljungman $\mathrm{P}$, et al. Impact of previous aspergillosis on the outcome of bone marrow transplantation. Clin Infect Dis. 1998;26:1098-1103.

14. Caillot D, Casasnovas O, Bernard A, et al. Improved management of invasive pulmonary aspergillosis in neutropenic patients using early thoracic computed tomographic scan and surgery. J Clin Oncol. 1997;15:139-147. doi:10.1200/jco.1997.15.1.139

15. Passera E, Rizzi A, Robustellini M, et al. Pulmonary aspergilloma: clinical aspects and surgical treatment outcome. Thorac Surg Clin. 2012;22:345-361. doi:10.1016/j.thorsurg.2012.04.001

16. Wang B-Y, Huang J-Y, Ko J-L, et al. A population-based cost analysis of thoracoscopic versus open lobectomy in primary lung cancer. Ann Surg Oncol. 2016;23:2094-2098. doi:10.1245/s10434-016-5125-3

17. Blyth CC, Palasanthiran P, O'Brien TA. Antifungal therapy in children with invasive fungal infections: a systematic review. Pediatrics. 2007;119:772-784. doi:10.1542/peds.2006-2931

18. Robinson LA, Reed EC, Galbraith TA, Alonso A, Moulton AL, Fleming WH. Pulmonary resection for invasive Aspergillus infections in immunocompromised patients. J Thorac Cardiovasc Surg. 1995;109:1182-1196; discussion 1196-1187. doi:10.1016/S00225223(95)70202-4

19. Bernard A, Caillot D, Couaillier JF, Casasnovas O, Guy H, Favre JP. Surgical management of invasive pulmonary aspergillosis in neutropenic patients. Ann Thorac Surg. 1997;64:1441-1447. doi:10.1016/ S0003-4975(97)00858-8
20. Baron O, Guillaume B, Moreau P, et al. Aggressive surgical management in localized pulmonary mycotic and nonmycotic infections for neutropenic patients with acute leukemia: report of eighteen cases. J Thorac Cardiovasc Surg. 1998;115:63-68; discussion 68-69.

21. Reichenberger F, Habicht J, Kaim A, et al. Lung resection for invasive pulmonary aspergillosis in neutropenic patients with hematologic diseases. Am J Respir Crit Care Med. 1998;158:885-890. doi:10.1164/ajrccm.158.3.9801056

22. Salerno CT, Ouyang DW, Pederson TS, et al. Surgical therapy for pulmonary aspergillosis in immunocompromised patients. Ann Thorac Surg. 1998;65:1415-1419.

23. Pidhorecky I, Urschel J, Anderson T. Resection of invasive pulmonary aspergillosis in immunocompromised patients. Ann Surg Oncol. 2000;7:312-317.

24. Yeghen T, Kibbler CC, Prentice HG, et al. Management of invasive pulmonary aspergillosis in hematology patients: a review of 87 consecutive cases at a single institution. Clin Infect Dis. 2000;31:859-868. doi:10.1086/318133

25. Al-Kattan K, Ashour M, Hajjar W, et al. Surgery for pulmonary aspergilloma in post-tuberculous vs immuno-compromised patients. Eur J Cardiothorac Surg. 2001;20:728-733.

26. Matt P, Bernet F, Habicht J, et al. Short- and long-term outcome after lung resection for invasive pulmonary aspergillosis. Thorac Cardiovasc Surg. 2003;51:221-225. doi:10.1055/s-2003-42259
Infection and Drug Resistance

\section{Publish your work in this journal}

Infection and Drug Resistance is an international, peer-reviewed openaccess journal that focuses on the optimal treatment of infection (bacterial, fungal and viral) and the development and institution of preventive strategies to minimize the development and spread of resistance. The journal is specifically concerned with the epidemiology of antibiotic resistance and the mechanisms of resistance development and diffusion in both hospitals and the community. The manuscript management system is completely online and includes a very quick and fair peerreview system, which is all easy to use. Visit http://www.dovepress.com/ testimonials.php to read real quotes from published authors. 